\title{
Voltage Assessment in Distributed Network with Photovoltaic Plant
}

\author{
Niancheng Zhou ${ }^{1}$ and Jizhong $\mathrm{Zhu}^{1,2}$ \\ ${ }^{1}$ State Key Laboratory of Power Transmission Equipment \& System Security and New Technology, Chongqing University, \\ Chongqing 400044, China \\ ${ }^{2}$ R\&D Group, Alstom Grid Inc., 10865 Willows Road NE, Redmond, WA 98052, USA
}

Correspondence should be addressed to Jizhong Zhu, zhujz@hotmail.com

Received 6 August 2011; Accepted 5 September 2011

Academic Editors: P. Poggi and S. Senthilarasu

Copyright (๑) 2011 N. Zhou and J. Zhu. This is an open access article distributed under the Creative Commons Attribution License, which permits unrestricted use, distribution, and reproduction in any medium, provided the original work is properly cited.

This paper presents an approach to analyze the steady-state voltage change in distributed network with or without connection of Photovoltaic (PV) plant. Several scenarios are discussed: the voltage drop of distribution feeders with or without PV plant; the voltage impact in distributed network with different weather conditions; the impacts of PV power plant capacity on the voltage. A practical distribution system with PV plant in China is used for simulation. The results and analysis are reported.

\section{Introduction}

Generally, the distribution network is designed in order to operate in radial configuration with a single source. With this kind of network the power flows from the substation to the loads in every point of the grid [1-3]. Since the traditional energy sources are limited, the world has started to think seriously of some renewable energy sources such as solar and wind energy [4-8]. The distributed generation (DG) technologies are widely used, which work well with small-scale renewable energy resources like solar and wind power [9]. Since distributed generation is typically sited close to customer loads, it can help to reduce the number of transmission and distribution lines that need to be upgraded or built. Obviously, it reduces transmission and distribution losses. However, due to the introduction of the distributed generation, the distribution network has multiple sources, and it is possible to have power flow in reverse direction, from DG units to the substations. The reverse power flow is the main problem for the integration of the DG units. There are some new issues in a PV-connected system such as voltage, reliability, and harmonic. [10] conducted a reliability evaluation for the large-scale grid-connected photovoltaic systems. Reference [11] focuses on harmonic distortion assessment for a singlephase grid-connected photovoltaic system. Herein we address the voltage issue.
The introduction of a PV plant increases the voltage in its point of common coupling (PCC). The voltage level depends on the network configurations and the load conditions. It is proportional to the instantaneous produced power of the PV system [1]. In this case, the structure of the distribution network changes from the single source to multipower sources, and the size and direction of the power flow in the feeder may change, which lead to the change of the voltage profile on distribution feeders.

There are several voltage regulation methods in distribution system such as the change of the tap of on-load tap changer (OLTC), the use of capacitor, and the installation of voltage regulator for line drop compensation. With these methods, the voltage of the user end will be maintained within the specified voltage range.

Due to the connection of PV power plant to the distribution network, the structure of the distribution system changes from the single source to a multipower source pattern. The original program may not be able to meet the voltage requirements of distribution network after the distributed generators such as PV plants access to the distributed network. This is because the output power of PV plant is affected by the sunshine, temperature; and other weather factors. The PV output power that has characteristics of fluctuations and intermittent is prone to cause voltage fluctuations of the common connection point. So the impact of photovoltaic 
power on the power system must be assessed in order to ensure that the increasing application of photovoltaic power does not bring negative consequences to the users. This paper discusses the steady-state voltage distribution and dynamics of voltage fluctuation after photovoltaic power plants access to the distribution network. The proposed approach is applied to a practical distribution system with PV plant in China.

\section{Distribution Network Model}

It is well known that in the distribution network, the ratio of $R / X$ (resistance/reactance) is relatively big, even bigger than 1.0 for some transmission lines. In this case, $P-Q$ decoupled loadflow is invalid for distribution network load flow calculation. It will also be complicated and time consuming to use the Newton-Raphson loadflow because the distribution network is only a simple radial tree structure. Therefore, the power summation-based radial distribution network loadflow method is used as follows [3].

(1) Conduct optimal node order calculation for all redial network based on graph theory. Consequently, the feeder branches are divided into different layers according to the distance between the ordered node and "root of a tree" node.

(2) Calculate the branch real power and reactive power from the "top of a tree" node to the "root of a tree" node. That is from last layer to first layer.

(3) Compute the node voltage from the "root of a tree" node to the "top of a tree" node, that is, from first layer to last layer.

Figure 1 is a distribution feeder structure without PV plant, where the source is selected as the reference node with voltage $\dot{U}_{0}=U_{0} \mathrm{e}^{j 0}$. Figure 2 is a distribution feeder structure with PV plant. If photovoltaic power plant of node $k$ is in operation, the voltage drop of each node will be changed.

According to the model of Figure 1, the feeders have $n$ loads, which are evenly distributed, and each load is assumed to have the same value $P_{d}+j Q_{d}$. Let $m$ be any point on the feeder branch, the active and reactive load of point $m$ can be written as

$$
P_{m-n}+j Q_{m-n}=(n-m+1) P_{d}+j(n-m+1) Q_{d} .
$$

To simplify the calculation, the principle of superposition is applied to the voltage calculation of the feeders. This will consider the impact of both the main source and photovoltaic power plant on the distribution feeder. In this situation, the source of distribution feeder is equivalent to a voltage source that is in short-circuit status, while photovoltaic power plant is equivalent to the current source that is in open status.

\section{Voltage Calculation of Distribution Network}

3.1. Distribution Feeders without PV Plant. From Figure 1, the voltage drop at any point $\mathrm{m}$ on distribution line is

$$
\Delta U_{s m}=\Delta U_{s m f}+\Delta U_{s m l}
$$

where $\Delta U_{s m f}$ is the voltage loss caused by the equivalent load after point $m . \Delta U_{s m l}$ is the voltage loss caused by load before point $m$. Assume that the line between two nodes has the same length, the voltage loss from point $m$ to the end of the feeder can be written as follows:

$$
\Delta U_{s m l}=m(n-m+1) \frac{P_{d} R_{1}+Q_{d} X_{1}}{U_{N}},
$$

where $R_{1}$ and $X_{1}$ are the resistance and reactance of the line between two nodes, respectively. $U_{N}$ is the rated voltage.

Assume that each load is evenly distributed at the midpoint of each line section, the voltage loss from the source to the point $m$ can be written as follows:

$$
\Delta U_{s m l}=\frac{m}{2}(m-1) \frac{P_{d} R_{1}+Q_{d} X_{1}}{U_{N}} .
$$

The total voltage loss at node $m$ is

$$
\Delta U_{s m}=\frac{m}{2}(2 n-m+1) \frac{P_{d} R_{1}+Q_{d} X_{1}}{U_{N}}, \quad k \in[1, n] .
$$

Thus, the node voltage at any point $m$ on the distribution feeders without PV power plant can be calculated as below:

$$
U_{m}=U_{0}-\frac{m}{2}(2 n-m+1) \frac{P_{d} R_{1}+Q_{d} X_{1}}{U_{N}}, \quad m \in[1, n] .
$$

3.2. Distribution Feeders with PV Plant Only. If the feeder side of the main power is short circuit, the impedance of the circuit is very small relative to the loads on distribution feeders. Thus, the PV power plant has no direct impact on node voltage loss after node $k$ (between point $k$ to load $n$ ), but has indirect impact since the voltage of node $k$ is improved due to the access of PV plant. At this point, the grid-connected PV power plant provides sole injection power, and the loss of line voltage is negative: the voltage loss of node $m$ can be expressed as follows:

$$
\begin{gathered}
\Delta U_{\mathrm{pv}}=-m \frac{P_{\mathrm{pv}} R_{1}+Q_{\mathrm{pv}} X_{1}}{U_{N}}, \quad m \in[1, k], \\
\Delta U_{\mathrm{pv}}=-k \frac{P_{\mathrm{pv}} R_{1}+Q_{\mathrm{pv}} X_{1}}{U_{N}}, \quad m \in[k+1, n] .
\end{gathered}
$$

3.3. Distribution Feeders with PV Plant. By using the superposition theorem, the voltage loss of the distribution feeders 


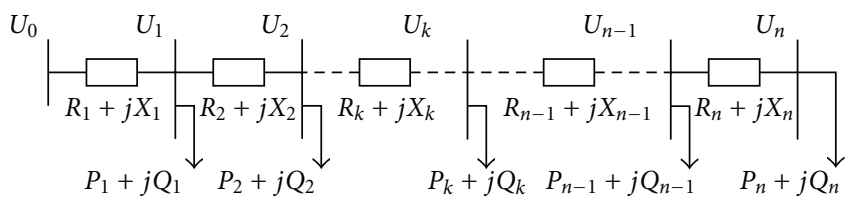

FIGURE 1: Distribution feeders without PV power plant.



FIgURE 2: Distribution feeders with PV power plant.

with photovoltaic power plants can be obtained by

$$
\begin{aligned}
\Delta U_{m}= & \frac{m}{2}(2 n-m+1) \frac{P_{d} R_{1}+Q_{d} X_{1}}{U_{N}} \\
& -m \frac{P_{\mathrm{pv}} R_{1}+Q_{\mathrm{pv}} X_{1}}{U_{N}}, \quad m \in[1, k], \\
\Delta U_{m}= & \frac{m}{2}(2 n-m+1) \frac{P_{d} R_{1}+Q_{d} X_{1}}{U_{N}} \\
& -k \frac{P_{\mathrm{pv}} R_{1}+Q_{\mathrm{pv}} X_{1}}{U_{N}}, \quad m \in[k+1, n] .
\end{aligned}
$$

Therefore, the node voltage at any point $m$ on the distribution feeders with PV power plant can be calculated as below:

$$
\begin{aligned}
U_{m}= & U_{0}-\frac{m}{2}(2 n-m+1) \frac{P_{d} R_{1}+Q_{d} X_{1}}{U_{N}} \\
& +m \frac{P_{\mathrm{pv}} R_{1}+Q_{\mathrm{pv}} X_{1}}{U_{N}}, \quad m \in[1, k], \\
U_{m}= & U_{0}-\frac{m}{2}(2 n-m+1) \frac{P_{d} R_{1}+Q_{d} X_{1}}{U_{N}} \\
& +k \frac{P_{\mathrm{pv}} R_{1}+Q_{\mathrm{pv}} X_{1}}{U_{N}}, \quad m \in[k+1, n] .
\end{aligned}
$$

It can be observed from (6), (9) that the node voltages of the distribution network have been enhanced when photovoltaic power plants access to the grid.

3.4. Consideration of PV Plant Capacity. Figure 3 is a distribution network with a PV plant, which is used to analyze the impact of the capacity of PV plant on node voltage. The value of each load is $P_{d}+j Q_{d}=0.42+j 0.24$.

The power factor of the output power of PV inverter is selected as 0.9 , and the data of PV power plant capacity are given in Table 1. If the access point of the PV plant is located at node 4 , the results of the voltage calculation for this distribution network are shown in Figure 4. It can be observed
$110 / 10.5 \mathrm{kV}$



FIgUre 3: A distribution network with a PV plant.

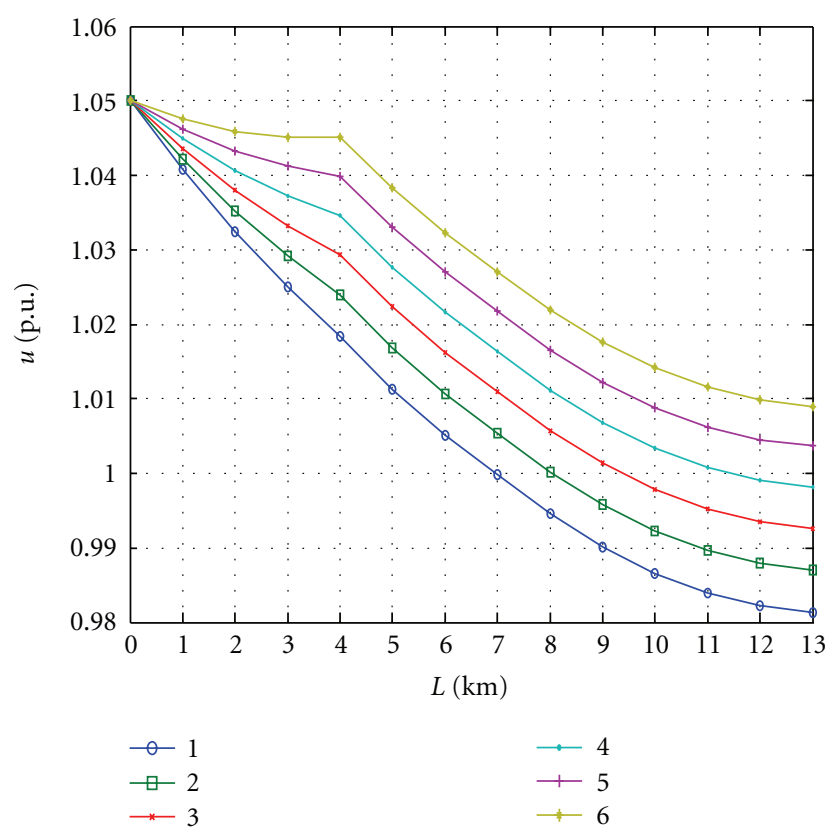

FIGURE 4: Voltage changes with different PV power plant capacity at node 4 .

from Figure 4 that the line voltage loss is reduced, and the feeder voltage is gradually increased as the increase of the capacity of photovoltaic power plant. 
TABLE 1: Capacity changes of PV power plant.

\begin{tabular}{lcccccc}
\hline Curve no. & 1 & 2 & 3 & 4 & 5 & 5 \\
\hline PV power (MVA) & $1+j 0.48$ & $3+j 1.45$ & $5+j 2.42$ & $7+j 3.39$ & $10+j 4.84$ & $15+j 7.26$ \\
$S_{\text {pv }} / S_{\text {load }}$ & $20 \%$ & $60 \%$ & $100 \%$ & $140 \%$ & $200 \%$ & $300 \%$ \\
\hline
\end{tabular}

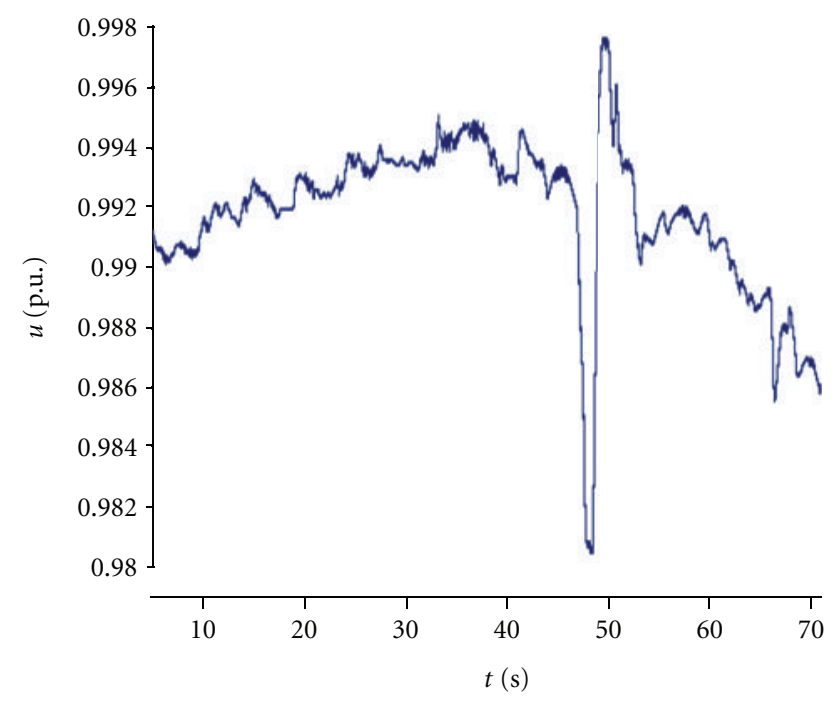

- Vrmsl

FIGURE 5: Voltage changes for Case 1 (weather: sunshine).

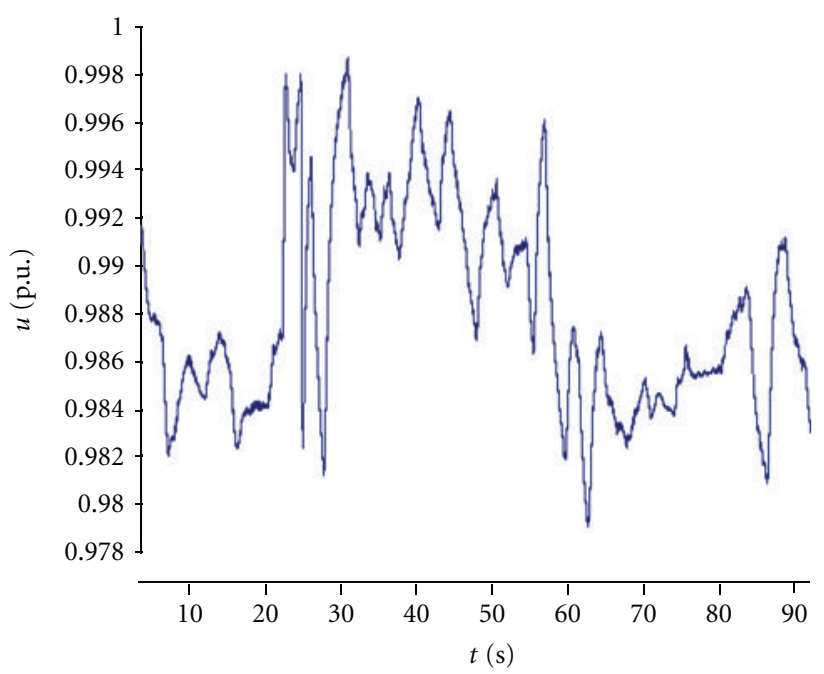

- Vrmsl

FIGURE 6: Voltage changes for Case 2 (weather: clouds).

Due to the increase of the capacity of PV power plant, more power output comes from photovoltaic power plant. Consequently, the voltage support is increased, and the feeder voltage is also increased. In Figure 4, voltage curve 6 has the highest peak among all the voltage distribution curves. It is noted that the feeder voltage will be over the standard deviation of the voltage if the capacity of PV power plant exceeds some level.

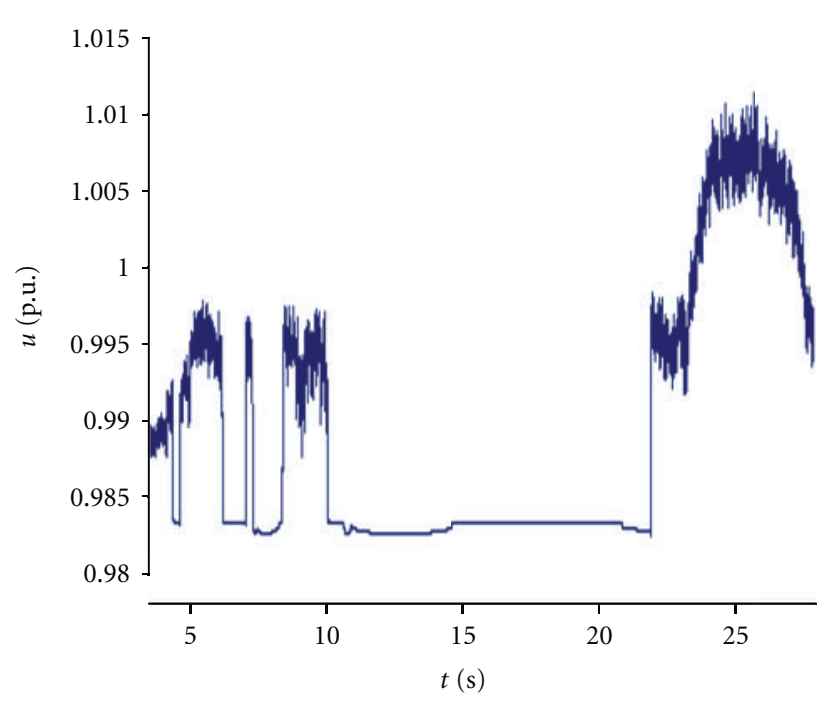

- Vrmsl

Figure 7: Voltage changes for Case 3 (weather: rain).

Unlike the traditional power plants that use coal or gas, the power output of a PV plant is often variable since the weather is changeable. Thus, the injection power from PV plant to distribution system cannot be fixed, which causes the fluctuations of voltage in distribution network.

\section{Simulation Results}

To analyze the impact of PV plant on distribution network, a practical $110 \mathrm{kV}$ distribution system with PV plant in China is used for simulation calculation. The capacity of PV plant is 1.0 MVA. The voltage of access point of PV plant is $380 \mathrm{kV}$.

Three different cases and data from the practical system are used in the simulation:

Case 1. Sunshine on November 24, 2009.

Case 2. Clouds on October 28, 2009.

Case 3. Rain on November 9, 2009.

The voltage changes for these three cases are computed and shown in Figures 5, 6, and 7, respectively.

It can be known from Figures 5-7 that the voltages of distribution network are relatively stable under the condition of sunshine. The fluctuations of the voltage are also smaller than those under the condition of clouds and rain. There is no PV power output during the daytime of rainy day. Thus, 
the corresponding node voltages for this situation are low (see Figure 7).

\section{Conclusion}

This paper discussed the problem of the PV power plant connecting to the distribution network. Several scenarios are discussed in the paper. They are the voltage drop of the distribution feeders with or without PV plant; the impacts of PV power plant capacity on the voltage curves. The steady-state voltage changes in distributed network with or without connection of Photovoltaic (PV) plant are analyzed based on a practical distributed system with PV plant in China. The simulation results show that that the voltages of distribution network are relatively stable under the condition of sunshine. The fluctuations of the voltage are also smaller than those under the condition of clouds and rain. There is no PV power output during the daytime of rainy day.

\section{Acknowledgments}

The project is sponsored by Hang Zhou Solar Energy Project and State Key Laboratory of Power Transmission Equipment \& System Security and New Technology, Chongqing University, China.

\section{References}

[1] A. Canova, L. Giaccone, F. Spertino, and M. Tartaglia, "Electrical impact of photovoltaic plant in distributed network," IEEE Transactions on Industry Applications, vol. 45, no. 1, pp. 341347, 2009.

[2] S. B. Kjaer, J. K. Pedersen, and F. Blaabjerg, "A review of singlephase grid-connected inverters for photovoltaic modules," IEEE Transactions on Industry Applications, vol. 41, no. 5, pp. 1292-1306, 2005.

[3] J. Z. Zhu, Optimization of Power System Operation, Wiley-IEEE Press, New York, NY, USA, 2009.

[4] G. Boyle, Renewable Energy, Oxford University Press in association with the Open University, 2004.

[5] R. Wengenmayr and T. Buhrke, Renewable Energy: Sustainable Energy Concepts for the Future, Wiley-VCH, 2008.

[6] G. M. Masters, Renewable and Efficient Electric Power Systems, Wiley-IEEE Press, New York, NY, USA, 2004.

[7] J. Zhu and K. Cheung, "Selection of wind farm location based on fuzzy set theory," in Proceedings of the IEEE PES General Meeting (PES '10), Minneapolis, Minn, USA, July 2010.

[8] L. Lin, N. Zhou, and J. Zhu, "Analysis of voltage stability in a practical power system with wind power," Electric Power Components and Systems, vol. 38, no. 7, pp. 753-766, 2010.

[9] W. El-Khattam and M. M. A. Salama, "Distributed generation technologies, definitions and benefits," Electric Power Systems Research, vol. 71, no. 2, pp. 119-128, 2004.

[10] G. Zini, C. Mangeant, and J. Merten, "Reliability of large-scale grid-connected photovoltaic systems," Renewable Energy, vol. 36, no. 9, pp. 2334-2340, 2011.

[11] A. Menti, T. Zacharias, and J. Milias-Argitis, "Harmonic distortion assessment for a single-phase grid-connected photovoltaic system," Renewable Energy, vol. 36, no. 1, pp. 360-368, 2011. 

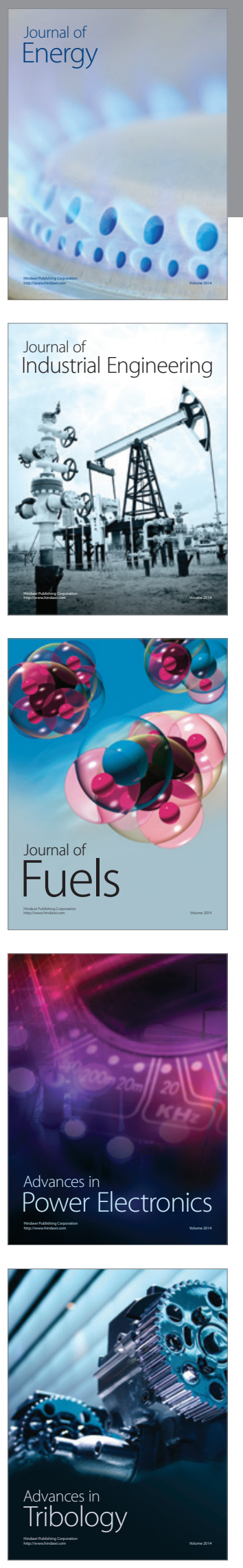
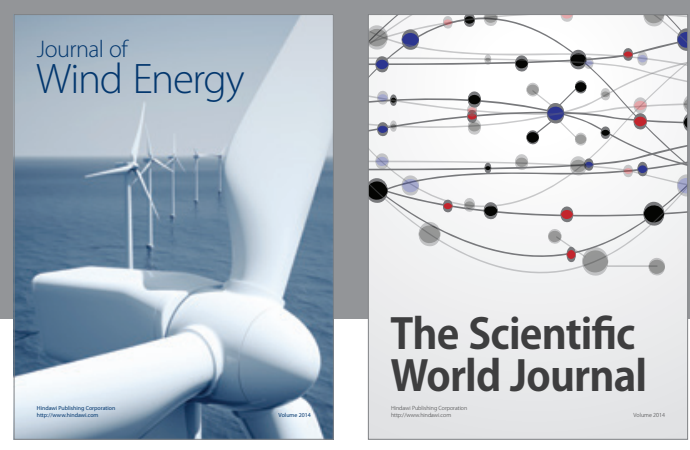

The Scientific World Journal

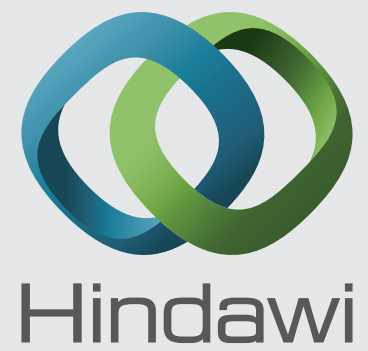

Submit your manuscripts at http://www.hindawi.com
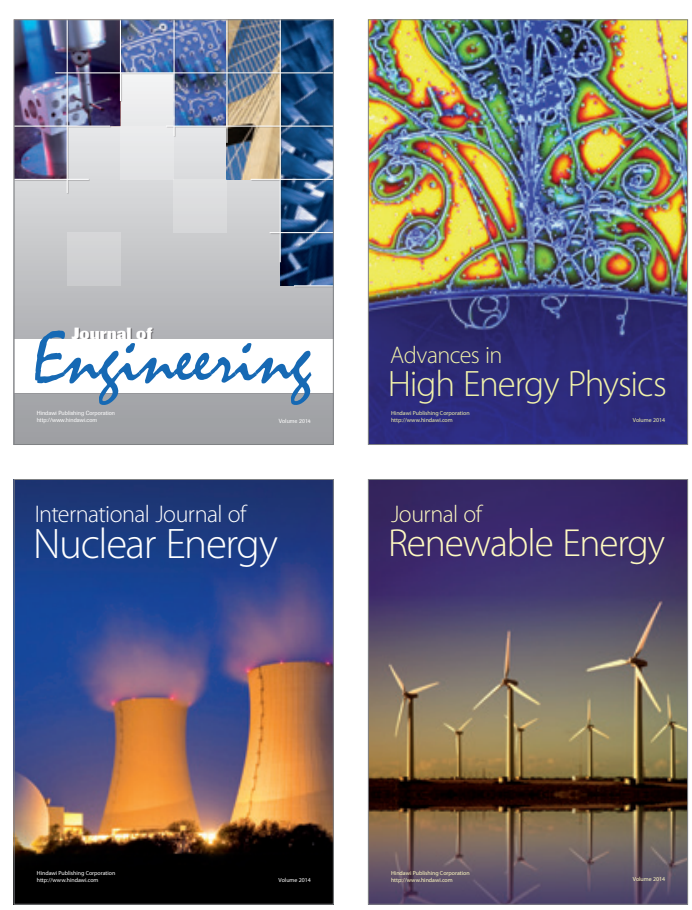

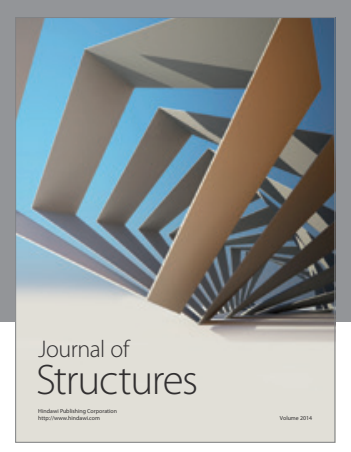

Rotating
Mechinery
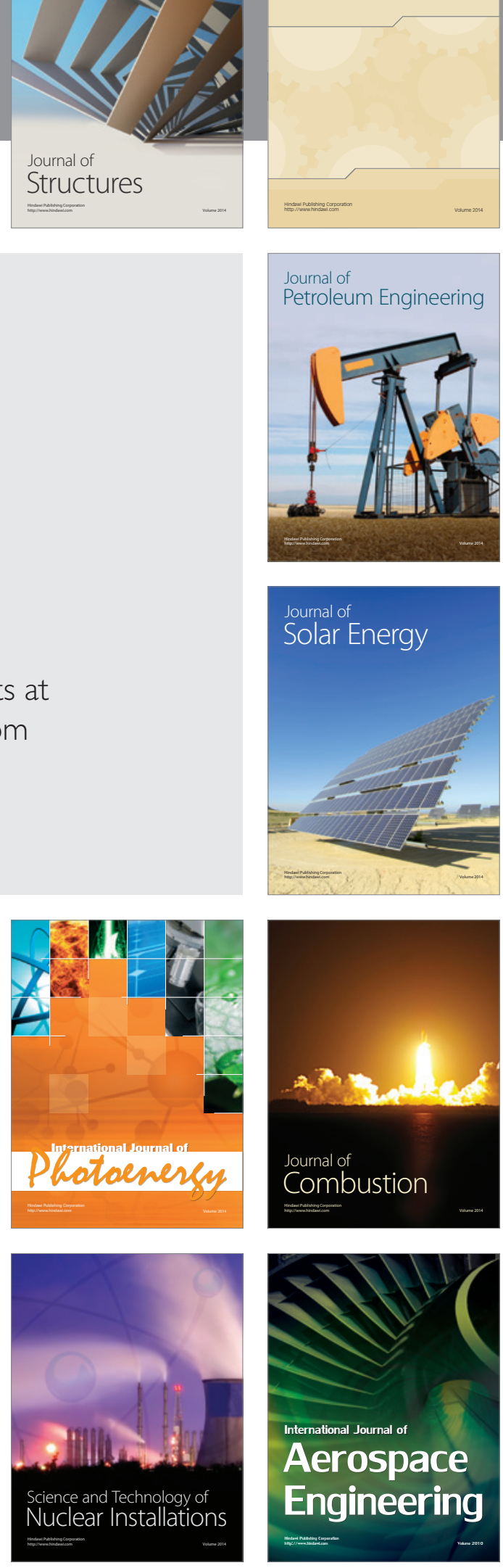